\title{
MEMANDIRIKAN SISWA AL AZHAR DALAM BERBISNIS DENGAN KETRAMPILAN BOGA
}

\author{
Wahyu Wiyani ${ }^{1)}$, Budi Siswanto ${ }^{2)}$, Dewi Astutty Mochtar ${ }^{3)}$ \\ ${ }^{1,2)}$ Fak Ilmu Sosial dan Ilmu Politik Universitas Merdeka Malang \\ ${ }^{3)}$ Fakultas Hukum Universitas Merdeka Malang \\ e-Mail : wahyuwiyani86@yahoo.com
}

\begin{abstract}
Abstrak
Diera saat ini untuk bisa memenangkan persaingan seorang siswa tidak hanya harus pintar dalam ilmu, namun juga harus ditunjang berbagai ketrampilan baik softskill maupun hardskill. Dengan softskill dan hardskill yang mumpuni seorang siswa setelah lulus pendidikan dasar tidak harus bekerja pada orang lain, namun bisa menciptakan lapangan pekerjaan bagi diri sendiri maupun orang lain., pendidikan dasar menjadi sesuatu yang memandirikan anak didik, terutama bagi kelompok miskin, anak didik akan menjadi mandiri ketika mereka dibekali keterampilan serta dekat dengan alam dan budayanya.

Secara softskill siswa Al Azhar telah banyak menerima pendidikan dari sekolah, namun secara hardskill masih minim dikarenakan fasilitas sekolah yang belum memadai. Dengan melihat latar belakang keluarga siswa kebanyakan pedagang maka pelatihan ketrampilan tata boga ini sangat cocok dilakukan dengan harapan hasil pelatihan bisa diterapkan siswa dan hasilnya bisa dijual orang tua mereka. Sehingga nantinya ketika mereka lulus dan tidak meneruskan pendidikan ke jenjang yang lebih tinggi mereka bisa menciptakan pekerjaan bagi dirinya dan memberikan penghasilan bagi dirinya.
\end{abstract}

Kata kunci : Pendidikan Dasar, Hardskill, ketrampilan Tata Boga

\section{PENDAHULUAN}

Pada tahun 2000, Indonesia bersama 189 negara anggota PBB ikut mengadopsi Deklarasi Milenium berikut tujuan-tujuan pembangunannya yang dikenal sebagai MDGs (Millenium Development Goals). Salah satu tujuan MDGs adalah mencapai pendidikan dasar untuk semua dengan target memastikan pada 2015 semua anak di manapun, baik laki-laki maupun perempuan dapat menyelesaikan pendidikan dasar. Berbeda dengan indikator MDGs global yang hanya menetapkan pendidikan dasar selama enam tahun, Indonesia menetapkan target yang lebih tinggi, yaitu sembilan tahun untuk pendidikan dasar. Hal ini mungkin mengacu pada asumsi yang berlaku umum. Semakin tinggi tingkat pendidikan seseorang akan lebih mudah baginya untuk memperoleh atau bahkan menciptakan lapangan kerja. Namun, aspek berikut ini perlu menjadi bahan pertimbangan. Harus diakui, secara umum pendidikan dasar sembilan tahun dengan kurikulum yang bersifat sangat umum, tidak memadai untuk mencetak anak didik yang memiliki keterampilan agar berdaya saing cukup dalam pasar tenaga kerja. Padahal, selama ini kelompok miskin sangat sulit menapaki jenjang hingga pendidikan tinggi agar memperoleh keterampilan yang dibutuhkan pasar tenaga kerja.

\section{Pendidikan di Indonesia}

Di Indonesia, kelompok miskin berada di manamana, baik di perkotaan maupun pedesaan, termasuk kawasan terpencil. Khusus untuk daerah pedesaan terpencil, selain kurangnya sarana pendidikan, jarak yang jauh dan mahalnya transportasi ke sekolah menjadi penyebab utama banyaknya anak dari keluarga miskin yang putus sekolah. Di Indonesia, Provinsi Papua mencapai angka putus sekolah dasar tertinggi, yaitu di atas 70 persen. Setidaknya terdapat empat faktor yang menjadi penyebab rendahnya tingkat partisipasi pendidikan menurut ILO 2011 :

1) Rendahnya akses pendidikan yang bersifat fisik, yakni fasilitas untuk mencapai sekolah

2) Keterjangkauan yang meliputi biaya langsung (uang sekolah), biaya tidak langsung (perlengkapan sekolah), dan biaya kesempatan (opportunity cost) bekaitan dengan waktu anak yang biasanya harus membantu orang tua dalam mencari nafkah.

3) Kualitas yang mencakup keterbatasan persiapan untuk memenuhi kebutuhan siswa dan pengiriman guru yang tidak mencukupi.

Relevansi, yakni masalah integrasi mata pelajaran lokal yang tidak memadai dan bahasa pengantar monolingual, yaitu hanya menggunakan Bahasa Indonesia. 


\section{Memandirikan}

Secara umum, dalam pendidikan di Indonesia mayoritas siswa terlalu diarahkan. Karena itu, muridnya bercita-cita menapaki jenjang pendidikan umum hingga ke universitas. Padahal, penduduk miskin dan kelompok menengah bawah yang merupakan mayoritas penduduk negeri ini, umumnya sangat sulit untuk bisa menuntaskan pendidikan hingga perguruan tinggi. kalaupun bisa menamatkan jenjang SMP dan SMA, mereka dipastikan sama sekali tidak memiliki keterampilan untuk bersaing dalam pasar tenaga kerja. Kita juga tak jarang mendengar cukup banyak sarjana yang bekerja serabutan atau berdagang di sektor informal, menjadi sopir taksi atau mengambil pekerjaan apa saja agar tidak menganggur. Tak heran, penyerapan tenaga kerja di Indonesia tergolong sangat rendah. Saat ini, sebanyak 32 persen dari 2.381.841 jumlah lowongan kerja yang terdaftar, ternyata tidak dapat terisi oleh para pencari kerja. Hal ini dipicu rendahnya tingkat pendidikan serta tidak sesuainya keahlian dan ketrampilan yang dimiliki pencari kerja dengan kualifikasi yang dibutuhkanperusahaan.

Sekaranglah saatnya kita harus bisa merubah model pembelajaran kita disekolah, tidak hanya ilmu tapi ketrampilan harus terus ditingkatkan untuk bekal siswa menapaki kehidupan berikutnya

\section{METODE KEGIATAN}

Minat siswa Yayasan Pendidikan Al Azhar untuk mengenyam pendidikan yang lebih tinggi dari tahun ketahun semakin membaik, hal ini terbukti dari siswa yang lulus SMP telah mendaftarkan diri ke SMA di yayasan yang sama telah mengalami peningkatan. Dengan semangat siswa untuk melanjutkan pendidikan ini, maka sudah saatnya yayasan pendidikan Al Azhar untuk membangun jejaring dengan perusahaan atau perguruan tinggi agar bisa membekali siswa mereka dengan berbagai ketrampilan sebagai bekal jika mereka telah lulus.

Yayasan Pendidikan Al Azhar selama ini telah bekerjasama dengan Unmer dan menjadi mitra LPPM Unmer dalam kegiatan pengabdian masyarakat maupun kegiatan KKN. Untuk saat ini kegiatan pengabdian berupa pelatihan ketrampilan Boga dengan peserta siswa SMP dan siswa SMA berjumlah 30 orang. Adapun kegiatan pengabdian yang dilakukan adalah:

\section{Pelatihan Ketrampilan Boga}

Ketrampilan tata boga diajarkan kepada siswa SMP dan SMA Al Azhar untuk mengasah ketrampilan anak didik dalam bidang pengolahan makanan serta mempersiapkan peserta didik untuk siap membuka peluang usaha jika telah lulus kelak. Ketrampilan yang diajarkan yaitu : ketrampilan membuat lemper isi tuna, puding sedot serta smoothy puding dan ketrampilan bekerja di dapur yang aman dan sehat.

\section{Adapun kegiatan yang dilakukan:}

\section{a. Pembuatan lemper isi tuna suwir}

\section{Bahan-bahan Lemper :}

- 250 gram ketan

- $250 \mathrm{ml}$ santan kental hasil parutan 1 butir kelapa

- 2 lembar daun salam

- 1 batang serai dimemarkan

- $1 / 2$ sendok teh garam

\section{Bahan Isian Lemper :}

- 250 gram ikan tuna kukus di suwir-suwir

- 1 lembar daun salam

- 3 lembar daun jeruk

- 1 lembar daun pandan, sobek-sobek

- 1 batang serai dimemarkan

- 30 lembar daun kemangi

- $200 \mathrm{ml}$ santan hasil parutan 1/2 butir kelapa

- 1 sendok teh garam

- $1 / 2$ sendok teh merica bubuk

- 1 sendok teh gula pasir

- 2 sendok makan minyak goreng

Bahan-bahan bumbu yang dihaluskan :

- 3 cabe merah besar

- 8 cabe rawit merah

- 5 siung bawang merah

- 4 siung bawang putih

- 5 butir kemiri disangrai

- 1 sendok teh garam

\section{Cara Membuat Kue Lemper Isi tuna Suwir Paling Enak :}

1. Ketan direndam selama 2 jam, lalu cucilah hingga bersih, dan tiriskan selanjutnya dikukus selama 15 menit, angkat.

2. Rebuslah santan bersama daun salam, garam serta serai, masukkan ketan yang telah dikukus dan aroni hingga seluruh santan meresap ke dalam ketan, angkat ketan lalu kukus ketang hingga matang dan angkat kembali.

3. Membuat Isian : Panaskan minyak tumislah bumbu yang telah dihaluskan hingga harum, 
selanjutnya masukkan suwiran tuna, pandan, daun jeruk, daun salam, serta serai. Tuangkan santan dan masaklah hingga matang dan santan habis terserap, tambahkan daun kemangi lalu aduk hingga rata dan angkat.

4. Siapkan cetakan lemper, olesilah dengan minyak atau lapisi cetakan dengan plastik yang bersih. Tuangkan setengah bagian ketan, ratakan lalu tuang bahan isian, ratakan dan tutup dengan setengah sisa ketan lalu padatkan. Ambil selembar daun pisang dengan ukuran yang sesuai dan bungkus bentuk lontong, kunci dengan lidi di masingmasing ujungnya, olesilah lemper dengan menggunakan minyak dan panggang hingga daunnya hangus, angkat dan sajikan hangat.

\section{b. Pembuatan Puding Sedot (Pudot)}

\section{Bahan-bahan}

1. 1 sachet nutrijel 15 gram (rasa jeruk atau lainnya)

2. $1 \mathrm{klg}$ skm putih

3. 3 buah jeruk pontianak peras airnya (bisa jeruk apa saja)

4. $2000 \mathrm{ml}$ air / 7 kaleng air

5. $3 \mathrm{sm}$ gula (sesuai selera)

6. $1 \mathrm{sm}$ tepung maizena

\section{Langkah}

Siapkan bahan bahan. Campur semua bahan jadi satu di dalam panci aduk rata hingga tercampur rata. Masak dengan menggunakan api kecil sambil diaduk aduk. Setelah matang tandanya mulai berbusa matikan. Tunggu agak dingin lalu pindahkan kedalam gelas atau botol. Siap disajikan

\section{c. Pembuatan Smoothy Puding}

\section{Bahan-bahan:}

1. 1 sachet poding 125 gram rasa coklat (atau lainnya)

2. $1 \mathrm{klg} \mathrm{skm} \mathrm{coklat}$

$3.8 \mathrm{klg}$ air

4. Coklat batangan

\section{Langkah}

Siapkan bahan. Campur semua bahan jadi satu dalam panci aduk hingga bercampur rata. Masak menggunakan api kecil. Setelah matang matikan. Biarkan agak dingin masukkan kedalam plastik wadah puding. Setelah itu letakkan coklat batangan yang telah dipotong tipis diatas puding. Tutup wadah kemasan puding. Siap disajikan

\section{GAMBAR KEGIATAN}

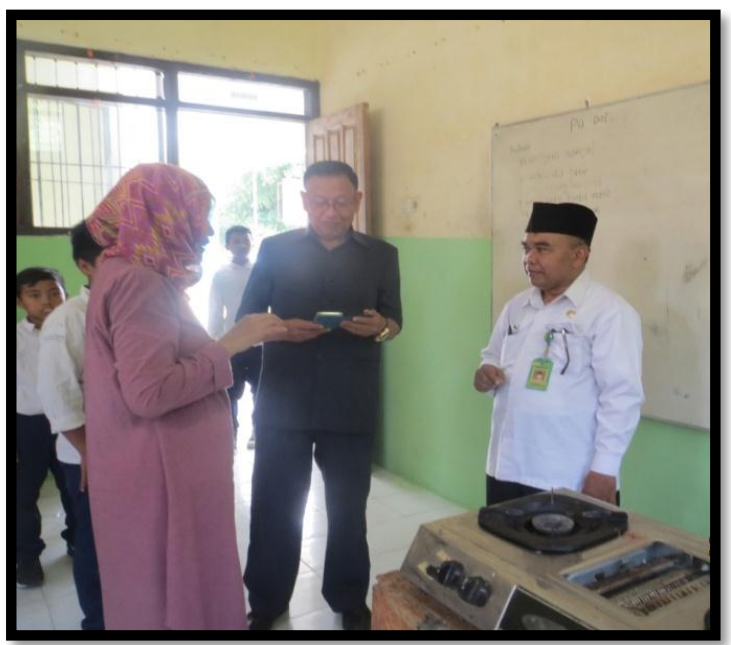

Gambar 1. Pertemuan denga ketua yayasan Al Azhar

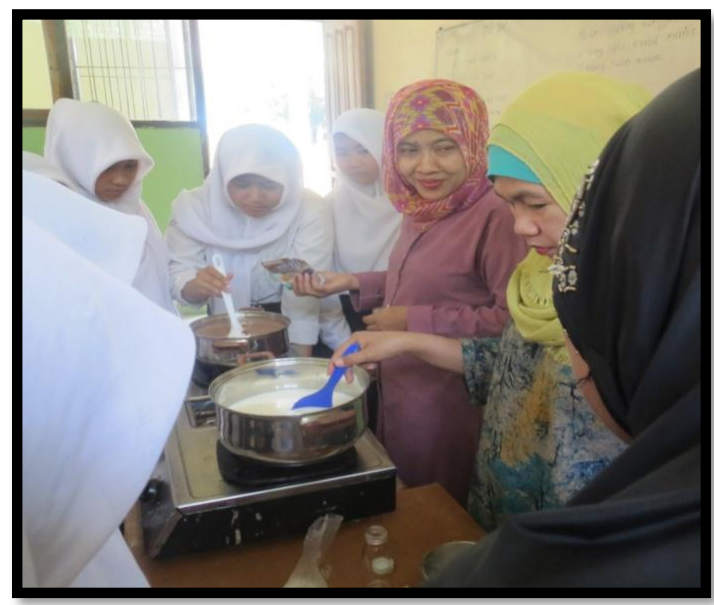

Gambar 2. Proses Pembuatan Pudot dan Smoothy
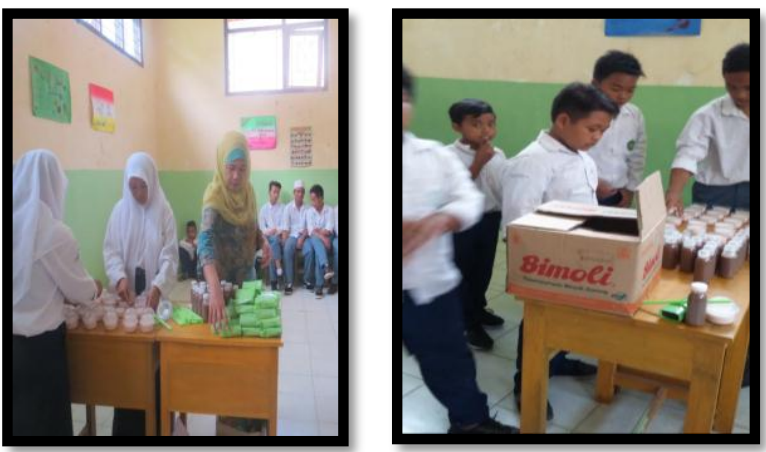

Gambar 3.4

Proses pengemasan Lemper dan pudot serta smoothy 


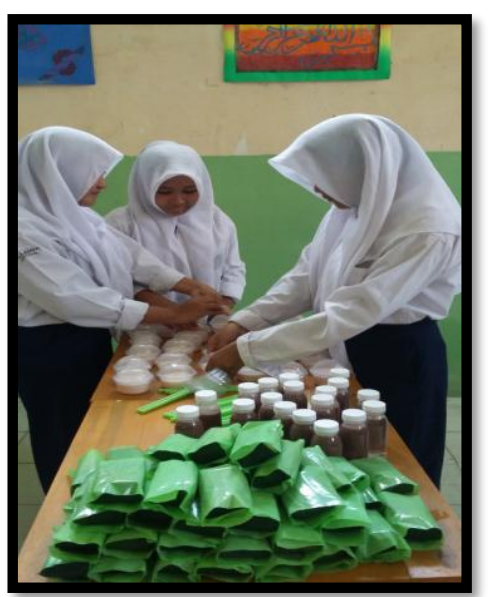

Gambar 5. Penutupan kemasan smoothy puding

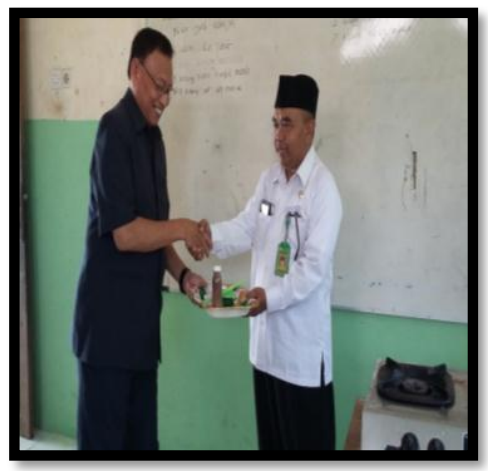

Gambar 6. Penyerahan hasil pelatihan pada ketua yayasan

\section{Pemberian Alat Peraga Edukatif Bagi Siswa TK}

Alat Peraga Edukatif atau yang biasa disebut APE adalah alat permainan yang dapat mengoptimalkan perkembangan anak sesuai dengan usia serta tingkat perkembangan anak itu sendiri. APE digunakan sebagai alat bantu guru dalam menyampaikan materi pengajaran agar memperjelas materi yang disampaikan serta memotivasi dan merangsang anak untuk bereksplorasi. "APE ini sangat berperan untuk merangsang kreativitas anak, mengenalkan suku kata dan pemberdaharaan kata kepada anak. APE merupakan alat permainan yang dirancang dan digunakan agar anak-anak dapat bermain dan belajar sehingga ada peningkatan dalam aspek perkembangan si anak, anak usia dini akan lebih nyaman belajar jika diikuti dengan gerakan dan permainan.

"Contohnya seperti permainan memasukan bendera yang bertuliskan nama buah ke dalam botol yang ditempel gambar buah tersebut, itu kan permainan namun anak-anak justru mendapatkan pembendaharaan kata dan tau jenisjenis buah,"

Dalam proses belajar mengajar di TK, anak juga harus dilatih kemampuan verbal dan bahasa, APE ini sangat baik jika diiringi dengan dengan komunikasi yang baik seperti dialog atau dongeng kepada anak. Hal ini sangat baik karena dapat meningkatkan kemampuan berbahasa, sosialisasi dan komunikasi anak dengan temannya dan gurunya. APE sesungguhnya alat peraga belajar berperan membawa dunia luar ke dalam kelas. Lingkungan luar yang sulit dijangkau oleh alat indra akan diperlihatkan dalam bentuk mini dan duplikatnya. Contohnya, tentang siang dan malam dapat dilihat dari lukisan tempel yang menunjukkan jika siang terang karena ada matahar, jika malam terang karena ada bulan
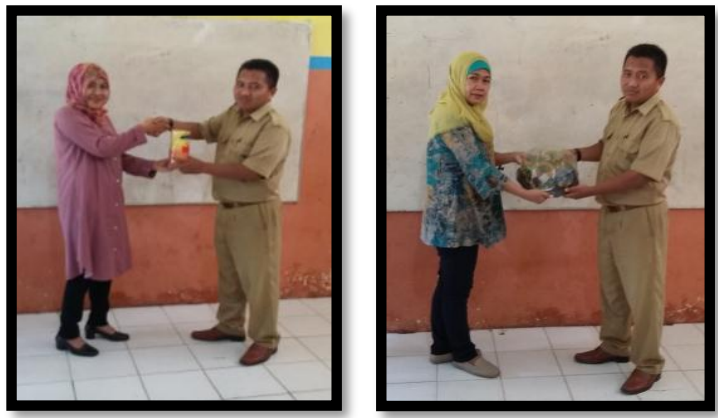

Gambar 7.8

Penyerahan Alat Peraga edukatif Bagi TK
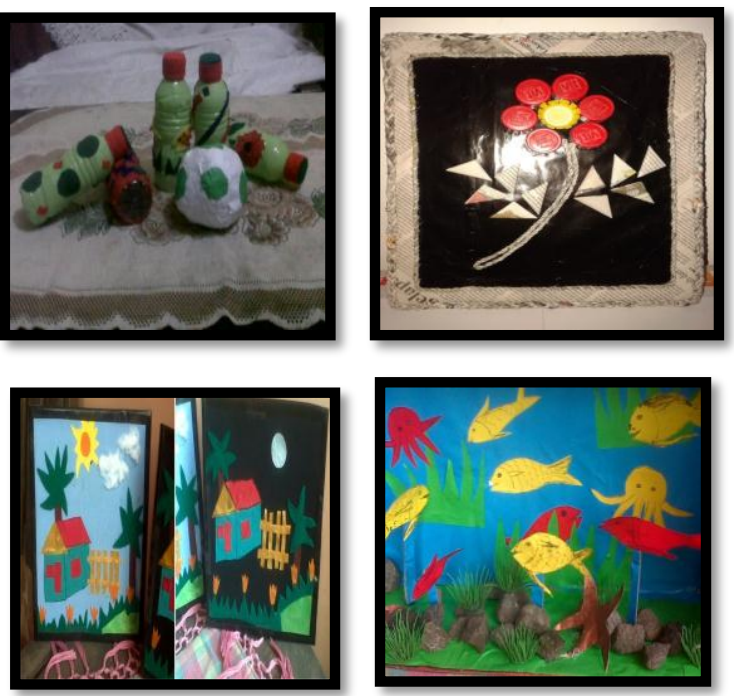

Gambar 9,10,11,12

Contoh Alat peraga Edukatif bagi TK 
3. Penyerahan Buku Sejarah Berdirinya Yayasan Al Azhar

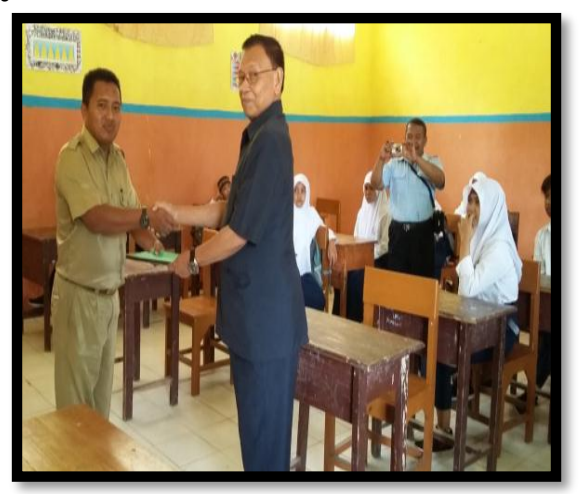

Gambar 13. Penyerahan Buku Sejarah Al Azhar

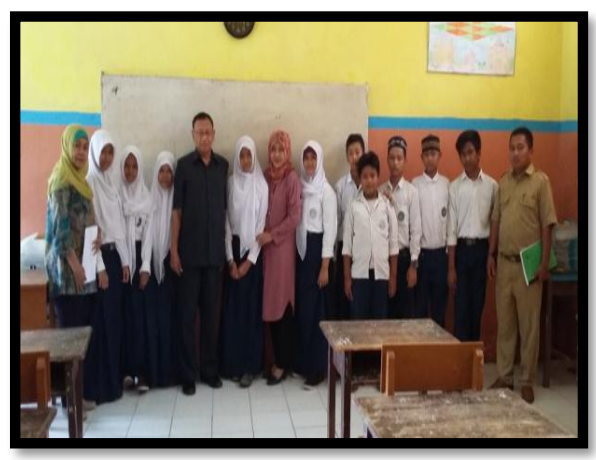

Gambar 14. Tim bersama Guru dan Peserta

\section{HASIL DAN PEMBAHASAN}

Ketrampilan merupakan salah satu modal bagi siswa untuk menapaki kehidupan selanjutnya setelah mereka lulus dari sekolah. Dengan berbekal ketrampilan mereka bisa menciptakan lapangan pekerjaan baik bagi diri mereka sendiri maupun lingkungannya. Beberapa kali kegiatan pelatihan dilakukan di sekolah Al Azhar sedikitnya bisa memberikan wawasan dan ketrampilan bagi mereka sehingga hardskill mereka bisa terasah. Kegiatan ketrampilan membuat aneka makanan dalam kesempatan ini adalah pembuatan lemper isi tuna suwir serta puding sedot dan smoothy puding disesuaikan dengang latar belakang ekonomi orang tua siswa yang mayoritas bekerja disektor informal dengan berjualan makanan, dengan harapan pelatihan tata boga yang diberikan akan sangat bermanfaat karena siswa bisa menghasilkan produk yang bisa dipasarkan melalui orang tua mereka

Selain memberikan pelatihan tata boga tim juga memberikan APE bagi siswa yang sebagian merupakan hasil karya siswa SMP dan SMA Al Azhar setelah menerima pelatihan dari tim sebelumnya. APE ini sangat bermanfaat bagi proses pembelajaran siswa TK, sangat disayangkan sekali apabila masyarakat masih memiliki mainset bahwa pendidikan anak usia dini tidak penting karena kegiatannya hanya bermain. Perlu dikatahui bahwa bermain merupakan kegiatan belajar yang tidak disadari oleh anak. Melalui bermain seluruh aspek perkembangan anak dapat dikembangkan. Mengapa di lembaga PAUD baik di luar maupun didalam ruang kelas selalu banyak mainan?

Mainan tersebut adalah sarana atau media pembelajaran untuk perkembangan anak. Media pembelajaran merupakan peralatan sebagai media untuk menyampaikan pesan dari guru kepada siswa. Pesan yang disampaikan adalah isi pembelajaran dalam bentuk tema/ topik pembelajaran saat itu. Dalam arti lain media pembelajaran dapat berupa alat permainan yang bersifat edukatif baik didalam maupun luar lingkungan sekolah. Kenapa menggunakan mainan? Karena yang dibutuhkan oleh anak usia dini adalah bukan dijejali teori mengenai bagaimana cara membaca, menilis maupun berhitung melainkan pembelajaran yang menyenangkan tanpa beban. Bagaimana cara mengenalkan dan menerapkan konsep baik angka maupun huruf pada anak merupakan tugas guru yang dapat dilaksanakan menggunakan media APE (Alat Permainan Edukatif) yang dalam pelaksanaannya dilakukan tanpa disadari oleh anak yaitu dengan cara bermain. Sehingga tidak menimbulkan tekanan pada anak. Selain itu adanya mainan-mainan tersebut dapat membantu anak untuk mengembangkan kemampuannya baik dalam konsep matematika dasar, kognitif, psiokomotor, bahasa maupun moral dan sosial melalui kegiatan eksperimen dan eksplorasi.

Adapun fungsi media pembelajaran (APE) yaitu:

a. Mengkonkretkan konsep-konsep yang abstrak

b. Menghadirkan objek-objek yang terlalu berbahaya atau sukar didapat ke dalam lingkungan belajar

c. Menampilkan objek yang terlalu besar

d. Memperlihatkan gerakan yang terlalu cepat.

e. Memungkinkan anak berinteraksi langsung dengan lingkungan.

f. Memungkinakan adanya keseragaman pengamatan atau persepsi belajr pada masingmasing anak.

g. Membangkitkan motivasi belajar anak

h. Menyajikan informasi belajar secara konsisten dan dapat diulang maupun disimpan menurut kebutuhan.

i. Menyajikan pesan atau info belajar secara serempak bagi seluruh anak

j. Memperjelas informasi pada waktu tatap muka dalam proses pembelajaran 
k. Mendorong motivasi belajar

1. Menambah pengertian nyata tentang suatu pengetahuan

m. Menambah variasi dalam menyajikan materi

n. Memberikan pengalaman, memeberikan wawasan yang lebih luas

o. Mencegah terjadinya verbalisme

p. Dapat menimbulkan semangat pembelajaran yang berlangsung menjadi lebih hidup.

q. Informasi sangat membekas, tidak mudah lupa

\section{KESIMPULAN}

\section{a. Kesimpulan}

Ketrampilan tata boga yang diberikan kepada siswa SMP dan SMA Al Azhar bertujuan untuk membekali mereka ketrampilan yang bisa dipergunakan untuk melatih siswa berbisnis, serta bekal kelak jika mereka telah lulus bisa membuka usaha sendiri.

Sementara bantuan APE untuk siswa TK sangat bermanfaat untuk proses belajar dan bermain bagi anak usia dini untuk memahami alam sekitar, dengan menggunakan miniatur alam.

\section{b. Saran}

Untuk mengasah ketrampilan siswa, yayasan Al Azhar hendaknya bisa menyediakan fasilitas pendukung serta membangun jejaring dengan pihak luar sehingga pelatihan ketrampilan bisa terus ditingkatkan dan siswa akan mendapatkan ilmu yang lebih banyak da bermanfaat

\section{REFERENSI}

Ifan A. Hadar, 2014, Pendidikan dasar menjadi sesuatu yang memandirikan anak didik. www.sinarharapan.co/news

Wiyani Wahyu, 2015, Dari Balck Gold untuk Pendidikan Anak Usia Dini, Jurnal ABM Mengabdi LPPM STIE Malangkucecwara ISSN 2477-6432

http://friscama.blogspot.co.id/2015/09/pentingn ya-alat-permainan-edukatif-bagi.html

http://www.matrapendidikan.com/2013/12/alatperaga-pembelajaran.html

http://cyberdakwah.com/2013/03/meneguhkankualitas-lulusan-pesantren/ 